\title{
Insulin Resistance and Angiotensin Converting Enzyme Polymorphism in Japanese Hypertensive Subjects
}

\author{
Junko Yamamoto, Shigeru Kageyama, Tatsuya Sakurai, Ken-ichi Ishibashi, Akira Mimura, \\ Kuninobu Yokota, Kazuo Aihara, Ikuo Taniguchi, Hiroaki Yoshida, and Naoko Tajima
}

\begin{abstract}
Renin-angiotensin system activity has been shown to affect insulin sensitivity. However, the relationship between $\mathrm{I} / \mathrm{D}$ polymorphism and insulin resistance is controversial. Therefore, we examined the relationship between the ACE genotype and insulin sensitivity in 51 Japanese hypertensive patients using the glucose clamp technique. The ACE genotype distribution in the hypertensive subjects was: 7 subjects with DD, 20 subjects with ID, and 24 subjects with II. Insulin sensitivity in terms of the glucose disposal rate was not significantly different among the three ACE genotypes, although there was a tendency for insulin sensitivity to decrease in the order of II, ID and DD, DD being the lowest. These findings are contrary to previous reports that insulin sensitivity was increased in normotensive subjects with the DD genotype who were Caucasian or African-American. There might be a difference due to race and whether the subjects are hypertensive or obese. We concluded that insulin sensitivity was not different among the ACE genotypes in the Japanese hypertensive subjects, supporting a previous report on the Chinese population. To date, insulin sensitivity has not been found to differ with ACE genotypes in the oriental population. (Hypertens Res 1999; 22: 81-84)
\end{abstract}

Key Words: insulin resistance, ACE polymorphism, glucose clamp, hypertension

The renin-angiotensin system plays an important role in blood pressure regulation and electrolyte balance. An association between hypertension and insulin resistance is now well recognized. Some angiotensin-converting enzyme (ACE) inhibitors improve insulin resistance in hypertensive patients (1), whereas an exogenous angiotensin II infusion improves insulin sensitivity (2). Thus, the relationship between renin-angiotensin system activity and insulin resistance has yet to be determined.

Serum ACE activity is associated with the insertion (I)/deletion (D) polymorphism of intron 16 in the ACE gene. Half of the interindividual variations of $\mathrm{ACE}$ are determined by $\mathrm{I} / \mathrm{D}$ polymorphism in Caucasians (3). An association between the DD genotype and ischemic heart disease (4) and left ventricular hypertrophy (5) has been suggested. Although the ACE I/D polymorphism is suspected to affect insulin resistance, the relationship between them is controversial.

To date, insulin sensitivity has been reported to be increased in subjects with the DD genotype of high renin-angiotensin activity (6-8). Another report has shown that there is no relationship between the I/D polymorphism and insulin resistance (9)

Therefore, we investigated the relationship between ACE genotype and insulin sensitivity in
Japanese hypertensive patients using the glucose clamp technique.

\section{Subjects and Methods}

\section{Subjects}

The subjects were 51 Japanese male patients with untreated essential hypertension. Their blood pressure, measured in the sitting position at the outpatient clinic, had been over $160 / 90 \mathrm{mmHg}$ on at least 3 occasions over a 3-mo period. All subjects were otherwise in good health, as determined by case history, physical examination, and routine laboratory screening. None were diabetic as assessed by the 75 $\mathrm{g}$ oral glucose tolerance test, according WHO criteria. The study was approved by the Medical Research Review Board of Jikei University and informed consent was obtained from each subject.

DNA Analysis

Genomic DNA was extracted from peripheral leukocytes with a blood DNA kit (QIAGEN, Hilden, Germany) in accordance with the method described elsewhere (10). The ACE I/D genotype of the patients was determined by polymerase chain reaction (PCR) using a flanking primer pair that amplified a genomic DNA fragment of intron 16 in the ACE gene. To increase the specificity of DD

From the Division of Clinical Pharmacology and Therapeutics, Department of Internal Medicine, Jikei University School of Medicine, Tokyo, Japan.

Address for Reprints: Junko Yamamoto, M.D., Division of Clinical Pharmacology and Therapeutics, Department of Internal Medicine, Jikei University School of Medicine, 3-25-8 Nishi-shinbashi, Minato-ku, Tokyo 105-8461, Japan.

Received October 5, 1998; accepted in revised form February 9, 1999. 
genotyping, PCR amplifications were performed with an insertion-specific primer pair (11).

The flanking primer pair used was: 5'-CTGGAG ACCACTCCCATCCTTTC3' and 5'-GATGTGGC CATCACATTCGTCAGAT3'. PCR amplification products were obtained using $50 \mu$ l reactions $[1 \mathrm{mg}$ genomic DNA, 500 pmol of primers, $0.5 \mathrm{mM}$ each of deoxy-ATP, GTP, CTP, TTP, and $3 \mathrm{mM} \mathrm{MgCl}_{2}$; 1 unit of Taq DNA polymerase (Takara, Otsu, Shiga, Japan); $50 \mathrm{mM} \mathrm{KCl}$; $0.001 \%$ gelatin; $10 \mathrm{mM}$ Tris- $\mathrm{HCl}, \mathrm{pH} \mathrm{8.3;} \mathrm{and} \mathrm{5 \%} \mathrm{DMSO]} \mathrm{with} 10 \mathrm{~min}$ denaturation at $94^{\circ} \mathrm{C}$, followed by 30 cycles of $1 \mathrm{~min}$ at $94^{\circ} \mathrm{C}, 1 \mathrm{~min}$ at $58^{\circ} \mathrm{C}$ (annealing), and $2 \mathrm{~min}$ at $72^{\circ} \mathrm{C}$ (extension) in a thermal cycler (PC-700, ASTEC, Fukuoka, Japan). The reaction was terminated at $72^{\circ} \mathrm{C}$ for $2 \mathrm{~min}$. The amplified ACE gene fragments were separated by agarose-gel electrophoresis. Fragments without insertion (D allele) and with insertion (I allele) of $\sim 190$ and $\sim 490 \mathrm{bp}$, respectively, were identified on a $1.5 \%$ agarose-gel containing ethidium bromide.

The insertion-specific primer pair was $5^{\prime}$-TGGG ACCACAGCGCCCGCCACTAC3' and 5'-TCGC CAGCCCTCCCATGCCCATAA3'. PCR amplification products were obtained using $25 \mu \mathrm{l}$ reactions [0.5 mg genomic DNA; $500 \mathrm{pmol}$ of primers; 0.5 $\mathrm{mM}$ each of deoxy-ATP, GTP, CTP, TTP, and 1.5 $\mathrm{mM} \mathrm{MgCl}_{2} ; 0.5$ unit of Taq DNA polymerase; 50 $\mathrm{mM} \mathrm{KCl} ; 0.001 \%$ gelatin; $10 \mathrm{mM}$ Tris- $\mathrm{HCl}, \mathrm{pH} 8.3$, and $5 \%$ DMSO] with 1 min denaturation at $94^{\circ} \mathrm{C}$, followed by 30 cycles of $30 \mathrm{~s}$ at $94^{\circ} \mathrm{C}, 45 \mathrm{~s}$ at $67^{\circ} \mathrm{C}$ (annealing), and $2 \mathrm{~min}$ at $72^{\circ} \mathrm{C}$ (extension). While the reaction yields no products in the samples of DD genotype, only the I allele produces a 335-bp amplicon. The 335-bp fragment was detected on a $1.5 \%$ agarose-gel containing ethidium bromide.

\section{Measurement of Insulin Sensitivity}

The hyperinsulinemic euglycemic clamp technique was performed to assess insulin sensitivity in 45 subjects. Insulin $(300 \mathrm{mU} / \mathrm{ml})$ was infused at a rate of $40 \mathrm{mU} / \mathrm{m}^{2}$ body surface area per min with a syringe pump (Syringe Pump 1235, Atom, Tokyo, Japan) as described elsewhere (12). Blood glucose was maintained at the fasting level by infusing $20 \%$ glucose according to mode 9:1 of the artificial endocrine pancreas, Biostator (Life Science Instrument, IN, USA) (13). The glucose clamp was maintained for $120 \mathrm{~min}$. The glucose infusion rate during the last $30 \mathrm{~min}$ of the glucose clamp was used as an index of insulin sensitivity. Insulin sensitivity was determined by an artificial endocrine pancreas in 39 cases. In the other 6 cases, insulin sensitivity was determined according to the method of DeFronzo without the artificial endocrine pancreas due to the breakdown of the machine (14). Blood glucose was measured every $5 \mathrm{~min}$ with a glucose meter (Antsense II, Daikin, Osaka, Japan) and 10\% glucose was infused to maintain the fasting blood glucose level. The glucose solution was changed from $20 \%$ to $10 \%$ in order to avoid angialgia. As insulin was infused in exactly the same way using the same insulin infusate and the same infusion pump, data obtained by the 2 glucose clamp methods were treat- ed together.

Fasting plasma glucose, fasting immunoreactive insulin (IRI), total cholesterol, HDL cholesterol, and triglyceride levels were measured. The $75 \mathrm{~g}$ oral glucose tolerance test was performed another day after an overnight fast. AUC (area under the curve) for the plasma glucose (PG) and IRI were calculated by the trapezoidal rule.

\section{Statistical Analysis}

Results were expressed as mean \pm SEM. One way ANOVA was used for comparison of the I/D genotype, and other variables. When there was a significant difference among the groups by ANOVA, Fisher's PLSD test was used for comparison of the two groups. $P$-value less than 0.05 was considered significant.

\section{Results}

The ACE genotype distribution in the hypertensive subjects was: 7 subjects with DD, 20 subjects with ID, and 24 subjects with II (Table 1). The D allele frequency in the hypertensive subjects was 0.33 . The allele frequency was similar to other sample Japanese populations $(10,15)$.

Age, body mass index (BMI), and blood pressure were not significantly different among the three groups of ACE genotype. Insulin sensitivity decreased in the order of II, ID, and DD (II: $6.51 \pm$ $0.52 \mathrm{mg} / \mathrm{kg} \cdot \mathrm{min}$, ID: $6.29 \pm 0.46 \mathrm{mg} / \mathrm{kg} \cdot \mathrm{min}$, and DD: $5.51 \pm 0.49 \mathrm{mg} / \mathrm{kg} \cdot \mathrm{min}$, respectively) (Fig. 1), although the difference was not significant at $5 \%$. Fasting plasma glucose, fasting IRI, total cholesterol, triglyceride and AUC (area under the curve) for PG, AUC for IRI in the $75 \mathrm{~g}$ OGTT were not significantly different among the three I/D genotypes. HDL cholesterol levels in subjects with the DD genotype were significantly lower than those of ID or II $(p<0.05)$ (Table 1$)$.

\section{Discussion}

In this study the glucose clamp test was performed by Biostator in 39 cases, and by the method of DeFronzo in the other 6 cases due to the breakdown of the machine (14). Insulin was infused in exactly the same way using the same insulin infusate and the same infusion pump in the 2 glucose clamp methods. The coefficient of variation of blood glucose during the last $30 \mathrm{~min}$ of the glucose clamp test was $3.9 \pm 0.83 \%$ (mean $\pm \mathrm{SD}$ ) in 5 cases by the artificial pancreas and $3.82 \pm 0.31 \%$ in 5 cases by the method of DeFronzo, showing comparable stability. Therefore, the data obtained by the 2 glucose clamp methods were treated together.

In this study, insulin sensitivity in terms of the glucose disposal rate was not significantly different among the 3 groups of ACE genotype, although there was a tendency for insulin sensitivity to decrease in the order of II, ID and DD, DD being the lowest. These findings are contrary to previous reports that insulin sensitivity was significantly increased in those with the DD genotype $(6-8)$. 
Table 1. Characteristics of the Subjects in the Three ACE Genotypes

\begin{tabular}{|c|c|c|c|c|}
\hline & DD & ID & II & \\
\hline$n$ & 7 & 20 & 24 & \\
\hline Age (yr) & $42.7 \pm 3.6$ & $43.3 \pm 1.7$ & $46.0 \pm 1.2$ & n.s. \\
\hline BMI $\left(\mathrm{kg} / \mathrm{m}^{2}\right)$ & $22.9 \pm 0.6$ & $24.1 \pm 0.7$ & $24.6 \pm 0.6$ & n.s. \\
\hline BP (Systolic) (mmHg) & $152.3 \pm 1.8$ & $151.9 \pm 3.5$ & $155.9 \pm 2.5$ & n.s. \\
\hline BP (Diastolic) (mmHg) & $93.9 \pm 2.3$ & $99.5 \pm 1.6$ & $102.0 \pm 1.5$ & n.s. \\
\hline $\mathrm{FPG}(\mathrm{mg} / \mathrm{dl})$ & $93.6 \pm 2.8$ & $100.4 \pm 1.9$ & $97.2 \pm 2.0$ & n.s. \\
\hline Fasting IRI $(\mu \mathrm{U} / \mathrm{ml})$ & $6.3 \pm 1.1$ & $7.8 \pm 1.2$ & $6.9 \pm 0.7$ & n.s. \\
\hline AUC-PG $(\mathrm{mg} \cdot \mathrm{h} / \mathrm{dl})$ & $267.4 \pm 24.2$ & $288.9 \pm 13.9$ & $294.3 \pm 12.3$ & n.s. \\
\hline AUC-IRI $(\mu \mathrm{U} \cdot \mathrm{h} / \mathrm{ml})$ & $59.5 \pm 10.9$ & $75.8 \pm 11.0$ & $74.0 \pm 12.2$ & n.s. \\
\hline $\mathrm{TC}(\mathrm{mg} / \mathrm{dl})$ & $171.4 \pm 9.1$ & $200.7 \pm 5.4$ & $194.5 \pm 6.9$ & n.s. \\
\hline $\mathrm{TG}(\mathrm{mg} / \mathrm{dl})$ & $136.3 \pm 26.2$ & $121.3 \pm 17.9$ & $139.0 \pm 23.3$ & n.s. \\
\hline $\operatorname{HDLC}(\mathrm{mg} / \mathrm{dl})$ & $38.9 \pm 2.5$ & $52.9 \pm 2.9 *$ & $48.0 \pm 1.9^{*}$ & ${ }^{*} p<0.05 v s . \mathrm{DD}$ \\
\hline
\end{tabular}

Values were mean \pm SEM. BMI: body mass index, BP: blood pressure, FPG: fasting plasma glucose, IRI: immunoreactive insulin, AUC-PG: area under the curve for plasma glucose, AUC-IRI: area under the curve for IRI, TC: total cholesterol, TG: triglyceride, HDLC: high density lipoprotein cholesterol, n.s.: not significant.

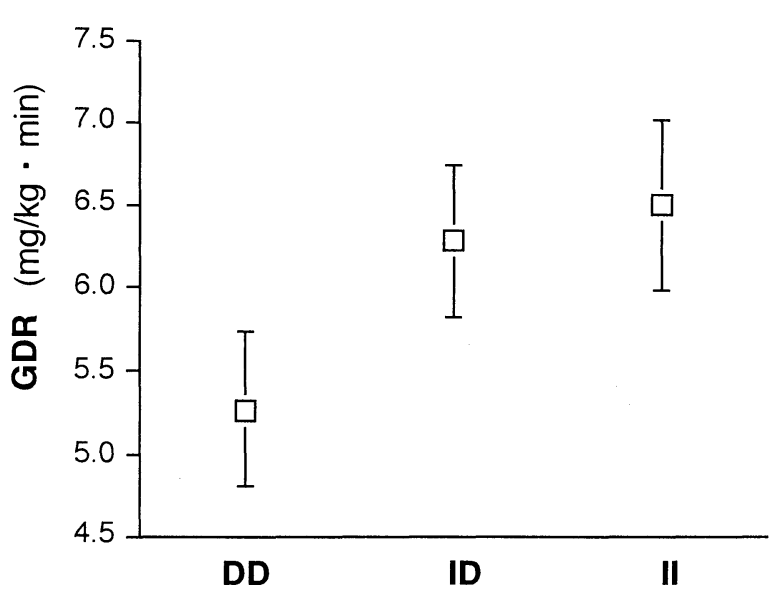

Fig. 1. Glucose disposal rate $(G D R)$ in the three genotypes. Data indicate mean $\pm S E M$.

Insulin sensitivity has been reported to be increased in with the normotensive African-Americans DD genotype using the glucose clamp technique (6). Nondiabetic and diabetic normotensive subjects with the DD genotype have also been reported to have a higher insulin sensitivity than those with the ID genotype as shown by the insulin suppression test, in which the races of the subjects were not specified (7). In another report, insulin sensitivity has been shown to be increased in Caucasian normotensive diabetic subjects with the DD genotype using the homeostasis model assessment (8). On the other hand, insulin sensitivity as assessed by the insulin suppression test was not significantly different among the 3 groups of ACE genotype in either normotensive or hypertensive Chinese subjects (9).

Thus, findings on the relationship between ACE genotype and insulin sensitivity are conflicting. The studies which revealed an increased insulin sensitivity with DD genotype were exclusively on normotensive Caucasian and African-American subjects. In another report, which has shown an increased insulin sensitivity with DD genotype, races of the subjects were not specified. However, as it is reported from the United States, the subjects would presumably be mainly Caucasians. On the other hand, the findings on the Chinese normotensive subjects, and ours on Japanese hypertensive subjects, as Oriental populations, have not shown a significant difference among the three groups of $\mathrm{ACE}$ genotype. Racial differences are observed regarding correlations between blood pressure and insulin resistance. A significant correlation between blood pressure and insulin sensitivity is observed in Caucasians, but not in Pima Indians and AfricanAmericans (16). Therefore, there might be a racial difference in the relationship between insulin sensitivity and ACE genotype.

The African-American and Caucasian subjects were normotensive. BMI were $28-29 \mathrm{~kg} / \mathrm{m}^{2}$ in the African-Americans and $29-31 \mathrm{~kg} / \mathrm{m}^{2}$ in the Caucasians, showing that they were obese. On the other hand, the Chinese and Japanese subjects were not obese, BMI being less than $25 \mathrm{~kg} / \mathrm{m}^{2}$. Therefore, insulin sensitivity was increased in subjects with the DD genotype only when they were normotensive and obese. As obese subjects are generally more insulin resistant, obesity would affect the results. A multiple regression analysis with GDR being a dependent variable, and ACE genotype and BMI being independent variables, showed a significant correlation between insulin sensitivity and BMI $(r=$ $0.58, p<0.001)$. By correcting insulin sensitivity by BMI, analysis of covariance showed that insulin sensitivity is $4.70 \pm 0.73 \mathrm{mg} / \mathrm{kg} \cdot \mathrm{min}$ in $\mathrm{DD}, 6.34 \pm$ $0.41 \mathrm{mg} / \mathrm{kg} \cdot \mathrm{min}$ in ID and $6.63 \pm 0.38 \mathrm{mg} / \mathrm{kg} \cdot \mathrm{min}$ in II, the DD group being significantly decreased compared to the ID group.

In the previous report in which insulin sensitivity 
was significantly increased with DD genotype compared to ID genotype, BMI was significantly lower in the DD subjects relative to the ID subjects (7). Therefore, if BMI were corrected among the groups, a significant difference in insulin sensitivity might not be observed. Also, in the report on African Americans, BMI was $1 \mathrm{~kg} / \mathrm{m}^{2}$ lower in the DD group than in the ID + II group. This significant difference might not be observed if the insulin sensitivity was corrected for BMI (6).

Infusions of angiotensin II have been reported to increase insulin sensitivity (2), which is compatible with the fact that the $\mathrm{D}$ allele is associated with higher insulin sensitivity. On the other hand, ACE inhibitors have been shown to improve insulin resistance in hypertensive patients, suggesting that high renin-angiotensin system activity decreases insulin sensitivity. In this context, it is probable that insulin sensitivity is decreased in those with the DD genotype, which has a higher serum ACE activity than ID or II genotype. However, ACE inhibitors inhibit not only the conversion of angiotensin I but bradykinin degradation, leading to vasodilatation. Improvement in insulin sensitivity by ACE inhibitors may be mediated via bradykinin.

It is known that angiotensin II formation is regulated not only by ACE but also by chymase. Chymase has been shown to produce approximately $60-70 \%$ of tissue angiotensin II (17). As tissue rather than circulating, angiotensin II would be a more important determinant for insulin sensitivity, the ACE genotype would have little effect on it. Further investigation is necessary to determine the relationship between renin-angiotensin system and insulin sensitivity.

In conclusion, we have shown that insulin sensitivity does not differ among the three ACE genotypes in Japanese hypertensive subjects, supporting the previous report on Chinese subject. However, insulin sensitivity, if corrected by BMI, was significantly decreased in patients with the DD genotype compared with the II genotype.

\section{Acknowledgements}

The authors are grateful to Ms. Y. Ichikawa and Ms. T. Etoh for their excellent technical assistance in the determination of ACE polymorphisms, and to Dr. M. Matsushima for his assistance in statistical analysis.

\section{References}

1. Berne C, Pollare $T$, Lithell $\mathrm{H}$ : Effects of antihypertensive treatment on insulin sensitivity with special reference to ACE inhibitors. Diabetes Care 1991; 14 (Suppl 4): 39-47.

2. Buchanan TA, Thawani H, Kades W, et al: Angio- tensin II increases glucose utilization during acute hyperinsulinemia via a hemodynamic mechanism. $J$ Clin Invest 1993; 92: 720-726.

3. Rigat B, Hubert C, Alhenc-Gelas F, Cambien F, Corvol P, Soubrier F: An insertion/deletion polymorphism in the angiotensin I-converting enzyme gene accounting for half the variance of serum enzyme levels. J Clin Invest 1990; 86: 1343-1346.

4. Cambien F, Porter O, Lecerf L, et al: Deletion polymorphism in the gene for angiotensin-converting enzyme is a potent risk factor for myocardial infarction. Nature 1992; 359: 641-644.

5. Schunkert H, Hense JW, Holmer SR, et al: Association between a deletion polymorphism of the angiotensin-converting-enzyme gene and left ventricular hypertrophy. N Engl J Med 1994; 330: 1634-1638.

6. Chiu KC, McCarthy JE: The insertion allele at the angiotensin I-converting enzyme gene locus is associated with insulin resistance. Metabolism 1997; 46: 395-399.

7. Katsuya T, Horiuchi M, Cien, Y-DI, et al: Relations between delation polymorphism of the angiotensinconverting enzyme gene and insulin resistance, glucose intolerance, hyperinsulinemia, and dyslipidemia. Arterioscler Thromb Vasc Biol 1995; 15: 779-782.

8. Panahloo A, Andres C, Mohamed-Ail V, et al: The insertion allele of the ACE gene I/D polymorphism. Circulation 1995; 92: 3390-3393.

9. Jeng JR, Shieh SM, Harn HJ, Lee MMS, Sheu WHH, Jeng CY: Angiotensin I converting enzyme gene polymorphism and insulin resistance in patients with hypertension. J Hypertens 1997; 15: 963-968.

10. Yoshida H, Mitarai T, Kawamura T, et al: Role of the deletion polymorphism of the angiotensin converting enzyme gene in the progression and therapeutic responsiveness of $\mathrm{IgA}$ nephropathy. $J$ Clin Invest 1995; 96: 2162-2169.

11. Lindpaintner K, Pfeffer MA, Kreutz R, et al: A prospective evaluation of an angiotensin-convertingenzyme gene polymorphism and the risk of ischemic heart disease. $N$ Engl J Med 1995; 332: 706-711.

12. Kageyama S, Yamamoto J, Mimura A, et al: Comparison of effects of nicardipine and trichlormethiazide on insulin sensitivity in hypertensive patients. Am J Hypertens 1994; 7: 474-477.

13. Clemens AJ, Hough DL, D'Ozario PA: Development of the Biostator glucose clamping algorithm. Clin Chem 1982; 28: 1899-1904.

14. DeFronzo RJ, Tobin JD, Anders R: Glucose clamp technique: a method for quantifying insulin secretion and resistance. Am J Physiol 1979; 237: E214-E233.

15. Ishigami $\mathrm{T}$, Iwamoto $\mathrm{T}$, Tamura $\mathrm{K}$, et al: Angiotensin I converting enzyme gene polymorphism and essential hypertension in Japan: ethnic difference of ACE genotype. Am J Hypertens 1995; 8: 95-97.

16. Saad MF, Lillioja S, Nyomba BL, et al: Racial difference in the relation between blood pressure and insulin resistance. $N$ Engl J Med 1991; 324: 733-739.

17. Okunishi H, Oka Y, Shiota N, Kawamoto T, Song $\mathrm{K}$, Miyazaki M: Marked species-difference in the vascular angiotensin II-forming pathways: Humans versus rodents. Jpn J Pharmacol 1993; 62: 207-210. 